\title{
A VIGÊNCIA DO IMPERIALISMO NA GLOBALIZAÇÃ̃o
}

\author{
CARLOS CESAR ALMENDRA ${ }^{1}$
}

Entre janeiro e junho de 1916, Lênin escreveu uma de suas obras mais influentes: Imperialismo: Fase Superior do Capitalismo na qual expôs cinco características fundamentais para definir o imperialismo. Tais características foram emblemáticas para as análises conjunturais dos diversos movimentos da esquerda brasileira e mundial no que se referia à explicação da realidade durante o século XX.

Logo após a queda do Leste Europeu, no início da década de 90, o anticomunismo proliferou-se - sobretudo no meio universitário - e o ideário do imperialismo foi sendo substituído pela linguagem da nova ordem mundial, ou seja, a globalização. Falar em imperialismo nos circuitos acadêmicos era démodé, sinônimo de linguagem de "dinossauro", adjetivo por sinal muito utilizado pelos antimarxistas.

A questão que nos remete a refletir é a seguinte: será que o imperialismo tinha, de fato, acabado juntamente com a queda do Leste Europeu? Antes mesmo de analisar, pari passu, se as cinco características tinham se esgotado, na incontinente e cega exaltação da globalização e do mercado, ignorava-se o imperialismo, como se fosse coisa do passado. Não se questionava se a globalização seria uma autodenominação fetichizada do capital

\footnotetext{
${ }^{1}$ Professor de Sociologia e História Econômica no Centro Universitário Fundação Santo André (CUFSA) e Mestre pelo Programa de Integração da América Latina (PROLAM/USP).
} 
que, portanto, obstruía a compreensão do mundo. Nada melhor do que retomar as características apontadas por Lênin e mostrar a contraproducência dos antimarxistas de plantão.

\section{1) concentração da produção e do capital atingindo um grau de desen- volvimento tão elevado que origina os monopólios cujo papel é decisivo na vida econômica}

Nesta primeira característica, Lênin apontava que os monopólios nasciam da própria concorrência e consistiam num dos fenômenos mais importantes da economia do capitalismo moderno. Sem embargo, estes monopólios existem até hoje e travam entre si duelos titânicos. Temos hoje cinco setores cruciais monopolizados, quer na produção, quer na especulação e que são o sustentáculo do capital e conseqüentemente, do capitalismo vigente: a) Monopólio da tecnologia; b) Monopólio do acesso aos recursos naturais do planeta; c) Monopólio dos meios de comunicação; d) Controle do mercado financeiro mundial; e) Monopólio das armas de destruição em mas$\mathrm{sa}^{1}$. Se os monopólios se cristalizaram no início do século XX, no início do século XXI eles são maiores e mais poderosos e a luta contra a perspectiva do capital requer necessariamente o controle social dos três primeiros e a eliminação dos dois últimos.

\section{2) fusão do capital bancário e do capital industrial e criação, com base nesse "capital financeiro", de uma oligarquia financeira}

Se a produção é o lócus da criação da riqueza material, é na esfera financeira que se comanda, cada vez mais, a repartição e a destinação social desta riqueza. Assim, verifica-se esta mudança:

"Um dos fenômenos mais marcantes dos últimos 15 anos tem sido a dinâmica específica da esfera financeira e seu crescimento do investimento, ou do PIB (inclusive nos países da OCDE), ou do comércio exterior. Essa 'dinâmica' específica das finanças alimentase de dois tipos diferentes de mecanismos. Os primeiros referem-se à 'inflação do valor dos ativos', ou seja, à formação de 'capital fíc-

\footnotetext{
${ }^{1}$ Samir Amin, "The Future of Global Polarization”. In: Social Justice. New York, Primavera-Verão, vol. 23, nos 1-2, 1996, p.7-8.
} 
tício'. Os outros baseiam-se em transferências efetivas de riqueza para a esfera financeira, sendo o mecanismo mais importante o serviço da dívida pública e as políticas monetárias associadas a este. Trata-se de $20 \%$ do orçamento dos principais países e de vários pontos dos seus PIBs, que são transferidos anualmente para a esfera financeira. Parte disso assume então a forma de rendimentos financeiros, dos quais vivem camadas sociais rentistas."

Segundo os cálculos de 1994 do BIS ${ }^{3}$, US\$ 13 trilhões giram pelo mundo em velocidade jamais vista, ao comando de teclas de computador acionados por operadores interconectados on-line, 24 horas por dia, nas bolsas espalhadas pelo mundo. Num segundo este "capital errante" pode estar em Hong Kong, no outro aterrissa em Chicago, no seguinte, pode ter tomado o rumo de Milão, Bangcoc, São Paulo ou ter voltado para Hong Kong. O megainvestidor George Soros ganhou US\$ 1 bilhão em 1992, apostando contra a libra esterlina. Consequiências: a libra teve de ser desvalorizada e retirada do mecanismo de flutuação criado no mercado europeu. Sobre a força do capital financeiro, observa-se que:

"Em 1971, o volume de empréstimos internacionais de médio e longo prazo feitos pelo capital privado foi de 10 bilhões de dólares. Em 1995, ele chegou a 1,3 trilhão. Cresceu 130 vezes em apenas duas décadas e meia. Esse dinheiro pode pertencer a um pequeno poupador japonês ou a um superinvestidor como o Húngaro George Soros - e está financiando coisas tão diversas quanto uma fábrica no Ceará ou o déficit público nos Estados Unidos. Além desse dinheiro de médio e longo prazo, há outro, o dinheiro volátil, que gira pelos vários mercados financeiros, como o das bolsas de valores, do câmbio ou dos juros. Esse dinheiro rápido sustenta transações diárias entre 2 e 3 trilhões de dólares."4

\footnotetext{
${ }^{2}$ François Chesnais, A Mundialização do Capital. São Paulo, Xamã, 1996, p.15.

${ }^{3}$ Bank for Internacional Settlements - Banco para Pagamentos Internacionais.

4 “A roda global”. In: Veja, 03/04/96.
} 


\section{3) diferentemente de exportação de mercadorias, a exportação de capitais assume uma importância muito particular}

A exportação de capital não suprimiu a exportação de mercadorias, mas mudou a configuração da produção. A partir do momento que as filiais das grandes corporações se espalharam pelo mundo, o processo produtivo fragmentou-se de tal modo que a mercadoria não tem carteira de identidade, não tem pátria. Descobrir sua procedência tornou-se tarefa quase impossível.

O Ford é um carro de qual nacionalidade? Depende. A Ford americana é dona de $25 \%$ da Mazda japonesa, numa operação em que fabricam carros pequenos. Juntas, são sócias da coreana Kia Motors. A Kia vende peças para a Ford/Mazda e a Yamaha japonesa vende os motores. Todavia, o que aparece no final é um carro Ford. A Fiat lançou o Palio simultaneamente no Brasil, Argentina, Colômbia, Venezuela, Índia, Marrocos, Equador, Egito, Argélia e Vietnã.

As redes de pesquisa entre as multinacionais são tão complexas que é difícil dizer quem está projetando o quê. A IBM tem laboratórios na Suíça e no Japão. A Hewlett-Packard emprega cientistas na Austrália, Alemanha e Cingapura. Na Compaq componentes são fabricados na China, Taiwan, Cingapura, Coréia, Japão e Vietnã. Equipamentos de precisão para prática do hóquei no gelo são desenhados na Suécia, financiados pelo Canadá, montados na Dinamarca e vendidos na Europa. O material utilizado é uma liga metálica cuja estrutura molecular foi desenvolvida e patenteada nos EUA, sendo produzida no Japão. Essa trança tecnológica acabou por confundir até o Pentágono que em 1990 declarou não saber em que países são projetados e construídos uma grande parte dos componentes das armas nucleares (nos EUA a produção bélica é privada).

\section{4) formação de uniões internacionais monopolistas de capitalistas que partilham o mundo entre si}

Considerando-se as dez maiores corporações mundiais em 1996 Mitsubishi, Mutsui, Itochu, Sumimoto, General Motors, Marubeni, Ford, Exxon, Nissho e Shell -, seu faturamento conjunto correspondeu a US\$1,4 trilhão. Isto equivalia ao PIB conjunto de Brasil, México, Argentina, Chile, 
Venezuela, Colômbia, Peru e Uruguai. Metade dos prédios, máquinas e laboratórios desses grupos e mais da metade de seus funcionários estão em unidades fora do país de origem e $61 \%$ do seu faturamento era obtido em operações fora do país de origem.

Se o faturamento se expandir para as cem maiores corporações, verificava-se que um terço do comércio internacional (US\$ 1 trilhão em 1990) se referia à trocas entre unidades das multinacionais. Elas empregavam em 1990, 20\% da força-de-trabalho do setor secundário e terciário nos países periféricos e $40 \%$ dos países centrais.

\section{5) termo da partilha territorial do globo entre as maiores potências capitalistas}

Durante a II Internacional, Lênin, Trotsky, Hilferding, Bukhárin e Rosa Luxemburgo concordavam num ponto fundamental: na unidade da economia mundial no sentido de uma integração cada vez mais estreita de todas as partes, moldado pelo capital e dominado pelos países capitalistas centrais. Depois das duas guerras mundiais e da guerra fria, o planeta tem sua dinâmica geopolítica e geoeconômica regido sob a égide do G-7 $7^{5}$. Este domínio, é um imperialismo de cartão de crédito, ${ }^{6}$ no qual existe uma cumplicidade entre os países capitalistas centrais para a administração e manutenção da ordem econômica, haja vista sua crise estrutural. A cumplicidade é necessária para que diante da crise e colapso econômico de um determinado país, os demais socorram-no, fazendo com que o colapso não se transforme em bola de neve, afetando toda a economia mundial. Como exemplo temos a queda da bolsa de valores de 1987, muito superior à de 1929, mas que não provocou um crack na economia mundial, bem como a crise mexicana de 1995 que, sob a coordenação dos EUA via FMI e Banco Mundial, que socorreram rapidamente com empréstimos de US\$ 50 bilhões para evitar um "efeito cascata", alastrando esta crise para outros países. Este mesmo tipo de socorro foi dado em 1997 na crise dos Tigres Asiáticos.

${ }^{5}$ Em 1997 transformou-se em G-8, quando a Rússia foi incorporada por ser uma potência nuclear em troca da maior expansão da OTAN.

${ }^{6}$ István Mészáros, Beyond Capital. Londres: Merlin, 1995, p. 956. 
Hoje, a globalização apresenta-se como um mundo rebrilhante, pletora luminosa de mercadorias em todos os cantos do mundo, cujo universo alcançou a cintilação perene das estrelas. Isto porque, sob o ponto de vista de seus defensores mais vorazes, foi exorcizado o espectro comunista que bloqueava a expansão capitalista e impedia a plena consolidação do mercado. Estes mesmos defensores apresentavam o processo de globalização como algo irreversível e que deveria ser acompanhada por todos os países do mundo. Os apologetas elevavam a globalização à dimensão de Olimpo, tendo o mercado como seu deus dos deuses: Zeus. Desprezava-se o imperialismo, como se jamais tivesse existido. Lênin, ao evidenciar as cinco características, não estava tratando-as como modelos, tipos ideais, dogmas, paradigmas ou regras monolíticas mas, como categorias ontológicas. Não obstante, quando apontava cada característica do imperialismo, não estava inventando uma nova fórmula, ou criando um novo método. Estava fazendo uma abstração razoável, que é uma conceituação básica, que nos permite dar nome às coisas, pautado na própria realidade, tirando a mudez do empírico e através do sujeito cognoscente (ser social), entender a especificidade do objeto; neste caso, no que consistia o imperialismo. Estas características não se esvaeceram, pelo contrário, continuam presentes no tempo e no espaço e suas modificações se expressam na radicalização e aprofundamento de cada uma delas. Portanto, àquilo que os guardiões do capital designavam a partir da década de 90 como globalização continuava sendo o próprio imperialismo, e hoje por mais que os antimarxistas neguem ou ignorem, nada mais notório do que a realidade social para a constatação da vigência do imperialismo, mesmo porque os monopólios são maiores e mais poderosos, mais concentrados e centralizados; o capital financeiro é muito maior do que o capital produtivo; a migração do capital é mais intensa e com maior mobilidade; as fusões e aquisições das grandes corporações continuam e as grandes potências massacram ainda mais os países subsumidos. Isto quer dizer que, a luta daqueles que defendem a perspectiva do trabalho continua sendo, a luta contra o imperialismo. 